\title{
Influence of contraceptive pill and menstrual cycle on serum lipids and high-density lipoprotein cholesterol concentrations
}

\author{
P N M DEMACKER, R W B SCHADE, A F H STALENHOEF, P M J STUYT, A VAN'T LAAR
}

\begin{abstract}
The fluctuations of serum lipid and lipoprotein concentrations within one cycle were studied both in women using and not using oral contraceptives. High-density lipoprotein cholesterol decreased significantly from $1.47 \mathrm{mmol} / 1(57 \mathrm{mg} / 100 \mathrm{ml})$ to $1.30 \mathrm{mmol} / 1(50 \mathrm{mg} / 100 \mathrm{ml})$ during one contraceptive cycle in eight women and rose again to the initial value during the pill-free days. The mean concentration of total cholesterol also fell significantly as a result of the decrease of high-density lipoprotein cholesterol and of a not significant decrease of low-density lipoprotein cholesterol. The mean serum triglyceride concentration did not change significantly. The fluctuations in the concentration of serum lipids and lipoproteins in 10 women not using oral contraceptives were smaller than in the women using oral contraceptives and no significant changes in the concentrations were found during one cycle.

Thus, high-density lipoprotein cholesterol concentration decreases during each contraceptive cycle. The time of blood sampling during the cycle is, therefore, of vital importance in interpreting the effect of oral contraceptives on high-density lipoprotein cholesterol. In women not using oral contraceptives blood can be sampled on random days during the cycle.
\end{abstract}

\footnotetext{
Department of Internal Medicine, St Radboud Hospital, University of Nijmegen, The Netherlands

P N M DEMACKER, PHD, biochemist

R W B SCHADE, MD, consultant physician (present address: St Anna Hospital, Oss, The Netherlands)

A F H STALENHOEF, MD, consultant physician

P M J STUYT, MD, consultant physician

A VAN'T LAAR, MD, professor of medicine
}

\section{Introduction}

Epidemiological studies have shown a relationship between the use of oral contraceptives and an increased incidence of cardiovascular diseases. ${ }^{12}$ Furthermore, oral contraceptives appear to influence the concentrations of serum lipids and lipoproteins. ${ }^{34}$ Since these concentrations are related to the risk of coronary heart disease, ${ }^{5}$ precise knowledge of the effect of oral contraceptives is of the utmost importance.

The effect of oral contraceptives on high-density lipoprotein cholesterol is a particularly controversial subject, probably because of the qualitative and quantitative differences between the many formulations of drug combinations in use. ${ }^{6}{ }^{7}$ Moreover, in most of these studies blood samples were taken on random days of the contraceptive cycle. Furthermore, the concentrations of serum lipids and lipoproteins were assumed to be more or less constant during one cycle. This has, however, never been proved. We therefore studied possible changes in the concentrations of serum lipids and lipoproteins during one contraceptive cycle in women using oral contraceptives and also during one menstrual cycle in women not using them.

\section{Subjects and methods}

The 18 women participating in this study were healthy hospital employees with body weights within $10 \%$ of the norm. ${ }^{8}$ Eight women (mean age 27; range 22-36 years) had been using oral contraceptives for at least six months; these contained either 125-150 $\mu \mathrm{g}$ levenorgestrel (two women) or $250 \mu \mathrm{g}$ levenorgestrel (six women), both combined with $50 \mu \mathrm{g}$ ethinyloestradiol, and were taken for 21 consecutive days out of 28 . The other 10 women (mean age 30, range 24-37 years) did not use oral contraceptives. They had regular menstrual cycles (mean, 28 days; range, 24-32 days).

Blood samples were collected after an overnight fast under standardised conditions without stasis. In women using oral contraceptives blood samples were obtained twice weekly during one contraceptive cycle from six and only once weekly from two. In all these women the first blood sample was obtained on the first day of the contraceptive cycle. In women not using oral contraceptives, blood samples were obtained twice weekly during one menstrual cycle from seven and only once weekly in three. In all these women the first blood sample 
was obtained on the second day of the menstrual cycle. In both groups of women the values at the start of the succeeding cycle were also determined.

The contraceptive cycle was arbitrarily divided into four equal periods and the results between days $2-8,9-15,16-22$, and $23-28$ were compared with those on the first day of the cycle. The cycles of various lengths in the women not using the contraceptive pill were divided into four periods representing the menstrual, follicular ovulatory, and luteal phases. ${ }^{9}$ As the second period started on the third day of the menstrual cycle only one value was available for the first period. When more than one value was obtained for a given period for an individual woman, the mean of both samples was taken

Serum was separated by centrifugation 2-3 h after blood sampling, stored at $4{ }^{\circ} \mathrm{C}$, and analysed within six days. Cholesterol was determined with the enzymic catalase reagent and triglycerides by semiautomated colorimetry. ${ }^{10}$ High-density lipoprotein was determined with the heparin $/ \mathrm{Mn}^{2+}$ precipitation method; the high-density lipoprotein fraction was isolated at $12000 \times g .1011$ Low-density lipoprotein cholesterol, expressed in $\mathrm{mmol} / \mathrm{l}$, was calculated according to the Friedewald formula: low-density lipoprotein-cholesterol = total cholesterol - (high-density lipoprotein-cholesterol $+0.46 \times$ triglyceride). ${ }^{12}$

The statistical significance of differences was analysed by Student's $t$ test and Wilcoxon's test for paired observations. Results obtained with both tests agreed well. Differences were only considered significant when $p$ values were less than 0.05 in both tests.

\section{Results}

The results obtained during one cycle of women using or not using oral contraceptives are shown in the table. The values obtained at the start of the first and the succeeding cycles did not differ significantly within both groups. The values obtained during one cycle were

Concentrations $( \pm S D)$ of cholesterol, triglycerides, and low-density and highdensity lipoprotein cholesterol during one cycle in women using (group 1) and not using (group 2) oral contraceptives

\begin{tabular}{|c|c|c|c|c|c|}
\hline \multirow{2}{*}{$\begin{array}{l}\text { Serum } \\
\text { concentration } \\
(\mathrm{mmol} / \mathrm{l})\end{array}$} & \multicolumn{5}{|c|}{ Period of contraceptive or menstrual cycle } \\
\hline & 1st Day $†$ & $1+$ & 2 & $3 \S$ & 4 \\
\hline $\begin{array}{l}\text { Cholesterol } \\
\text { Triglycerides } \\
\text { Low-density }\end{array}$ & $\begin{array}{l}4.69(0.29) \\
0.89(0.24)\end{array}$ & $\begin{array}{l}\text { Group } 1(n \\
4.30(0 \cdot 14)^{* *} \\
0.87(0.33)\end{array}$ & $\begin{array}{l}z=8) \\
4.29(0.30)^{* *} \\
0.88(0.28)\end{array}$ & $\begin{array}{l}4.38(0.31)^{* *} \\
0.93(0.40)\end{array}$ & $\begin{array}{r}* 4.48(0.32) \\
0.78(0.21)\end{array}$ \\
\hline $\begin{array}{r}\text { lipoprotein } \\
\text { cholesterol } \\
\text { High-density }\end{array}$ & $2 \cdot 82(0 \cdot 17)$ & $2.53(0.21)^{*}$ & $2.56(0.42)$ & $2 \cdot 64(0 \cdot 30)$ & $2 \cdot 77(0 \cdot 26)$ \\
\hline $\begin{array}{l}\text { lipoprotein } \\
\text { cholesterol }\end{array}$ & $1 \cdot 47(0 \cdot 27)$ & $1 \cdot 37(0.25)^{*}$ & $1.33(0.29)^{* *}$ & $1 \cdot 30(0 \cdot 20)^{* *}$ & $* 1.35(0.27)$ \\
\hline $\begin{array}{l}\text { Cholesterol } \\
\text { Triglycerides } \\
\text { Low-density }\end{array}$ & & $\begin{array}{l}\text { Group 2(n } \\
5.16(0.93) \\
0.86(0.19)\end{array}$ & $\begin{array}{l}=10) \\
5.27(0.75) \\
0.84(0.19)\end{array}$ & $\begin{array}{l}5.18(0.64) \\
0.79(0.36)\end{array}$ & $\begin{array}{l}5.19(0.76) \\
0.88(0.31)\end{array}$ \\
\hline $\begin{array}{r}\text { lipoprotein } \\
\text { cholesterol } \\
\text { High-density }\end{array}$ & & $3 \cdot 17(0 \cdot 83)$ & $3.34(0.80)$ & $3.27(0.69)$ & $3.26(0 \cdot 75)$ \\
\hline $\begin{array}{l}\text { lipoprotein } \\
\text { cholesterol }\end{array}$ & & $1.52(0.30)$ & $1.54(0.31)$ & $1.55(0.33)$ & $1.52(0.34)$ \\
\hline
\end{tabular}

Significance of differences: $* 0.05<\mathrm{p}<0.1 \quad * * \mathrm{p}<0.05$.

+ Second day of menstruation (mean of two cycles) (group 2 only).

$\$$ Ovulatory phase (group 2 only).

Conversion: SI to traditional unit s-Cholesterol: $1 \mathrm{mmol} / 1 \approx 39 \mathrm{mg} / 100 \mathrm{ml}$.

Triglyceride: $1 \mathrm{mmol} / 1 \approx 90 \mathrm{mg} / 100 \mathrm{ml}$.

compared with the mean results on the first day of two contraceptive cycles and on the second day of menstruation of two menstrual cycles (see table). In women using oral contraceptives high-density lipoprotein cholesterol decreased during the contraceptive cycle from $1.47 \mathrm{mmol} / 1(57 \mathrm{mg} / 100 \mathrm{ml})$ to $1.30 \mathrm{mmol} / 1(50 \mathrm{mg} / 100 \mathrm{ml})(\mathrm{p}<0.05)$ and rose again to the starting value during the pill-free days. Total serum cholesterol concentrations also fell significantly during the cycle (maximum $0.40 \mathrm{mmol} / \mathrm{l}, \mathrm{p}<0.05$ ) as a result of the decrease in high-density lipoprotein cholesterol and a not significant decrease in low-density lipoprotein cholesterol. Concentrations of triglycerides did not change significantly.

In women not using oral contraceptives no significant changes in the concentrations of cholesterol, triglycerides, low-density and highdensity lipoprotein cholesterol were found during one cycle. For all the serum lipids and lipoproteins measured, the absolute differences in the individual subjects within one cycle between the highest and lowest mean concentrations of each cycle were more than twice as great in the women using oral contraceptives as in the non-users. The same was true for the fluctuations in the mean concentrations of the two groups (see table).

\section{Discussion}

Our data indicate that the moment of blood sampling during the contraceptive cycle is of vital importance in interpreting the concentrations of high-density lipoprotein cholesterol in women using oral contraceptives. We observed a tendency to lower high-density lipoprotein cholesterol concentrations after 2-8 days and significantly lower values after 9-22 days compared with those on the first day of the contraceptive cycle $(p<0.05)$. The effects of oral contraceptives on high-density lipoprotein cholesterol concentrations in women have been confused by the different types and combinations of doses of oestrogens and progestogens. ${ }^{6}$ ? In those studies in which high-density lipoprotein cholesterol values were similar to those of non-users or to control values in the same subjects, ${ }^{13-16}$ blood had been sampled on random days during the cycle. Decreased highdensity lipoprotein cholesterol concentrations in users of the contraceptive pill have also been found ${ }^{77^{1-19}}$; in three of these studies blood was sampled around the twenty-first day of the contraceptive cycle. Thus, not only the type of composition of the oral contraceptive pill but also the time of blood sampling during the cycle is important in obtaining lower high-density lipoprotein cholesterol values.

We also noticed lower low-density lipoprotein cholesterol values during the contraceptive cycle which tended to be significant in period 1. Similar or increased low-density lipoprotein cholesterol concentrations have been found compared with pretreatment values in women using different types of oral contraceptives. ${ }^{4} 713$

The fluctuations in high-density and low-density lipoprotein cholesterol in a normal menstrual cycle do not apparently show a clear pattern. The intraindividual variations in concentrations of cholesterol, triglycerides, and high-density lipoprotein cholesterol are, however, quite great. To obtain an accurate estimate in one individual, three determinations should be done if possible (unpublished observations). In our study only one value for each subject was available in the first period whereas for both groups of women an average of 1.7 and 1.8 measurements were recorded in the other periods. Thus, the values in the first period were less accurate. We therefore compared the results obtained during one cycle with the mean of both first periods and concluded that total concentrations of cholesterol and of low-density and high-density lipoprotein cholesterol during one cycle did not change significantly in women not using oral contraceptives. Other studies have shown a cyclical rise during the normal menstrual cycle, with the highest total cholesterol concentrations occurring at the ovulatory phase. ${ }^{920}$ Nevertheless, a cyclical decrease in total cholesterol, with the lowest values in the ovulatory or the luteal phases, has also been found. ${ }^{21-22}$ Slight but insignificant variations in low-density lipoprotein cholesterol concentrations during the cycle have also occurred. ${ }^{23}$ High-density lipoprotein cholesterol concentrations have increased during the cycle, ${ }^{22}{ }^{23}$ with significantly higher concentrations of $\mathrm{HDL}_{2}$ at ovulation and a decrease as menstruation approached. Thus published data are not consistent. These apparently conflicting results can, at least partly, be ascribed to the large variability in concentrations of serum lipids and highdensity lipoprotein cholesterol in women (results not yet published) and to the different groups of women studied. Our data show that in a group of hospital employees using oral contraceptives the fluctuations in the concentrations at each cycle period were slight and more than twice as small as in the women using oral contraceptives. Thus, in these women the time of blood sampling within one menstrual cycle was less important than in women who used oral contraceptives. 
We thank R T P Jansen, for statistical advice and Riky Vos and Anneke Hijmans for technical assistance.

Correspondence should be addressed: $\operatorname{Dr} P$ N M Demacker, Department of Internal Medicine, St Radboud Hospital, Geert Grooteplein Zuid 8, 6500 HB Nijmegen, The Netherlands.

\section{References}

${ }^{1}$ Royal College of General Practitioners. Oral contraception study. Mortality among oral contraceptive users. Lancet 1977;ii:727-31.

${ }^{2}$ Beral V. Cardiovascular-disease mortality trends and oral-contraceptive use in young women. Lancet 1976; ii:1047-51.

3 Nicoll A, Miller NE, Lewis BE. High-density lipoprotein metabolism. $A d v$ Lipid Res 1980;17:95.

4 Wallace RB, Hoover J, Barrett-Connors E, et al. Altered plasma lipid and lipoprotein levels associated with oral contraceptive and oestrogen use Lancet 1979; ii:111-4.

${ }^{5}$ Rhoads GG, Gulbrandsen CL, Kagan A. Serum lipoproteins and coronary heart disease in a population study of Hawaii Japanese men. $N$ Engl $\mathcal{F}$ Med 1976;294:293-8.

- Bradley DD, Wingerd J, Pettiti DB, Krauss R, Ramcharan S. Serum highdensity-lipoprotein cholesterol in women using oral contraceptives, estrogens and progestins. $N$ Engl f Med 1978;299:17-20.

- Rössner S, Frankman O, Marsk L. Effects of ethinylestradiol/D-norgestrel combinations on serum lipoproteins. Acta Obstet Gynecol Scand 1980 $59: 255-8$.

8 Metropolitan Life Insurance Co. Statistical Bulletin 1959;40:1.

- Adlercreutz H, Tallqvist G. Variations in the serum total cholesterol and hematocrit values in normal women during the menstrual cycle. Scand f Clin Lab Invest 1959;11:1-9.

10 Demacker PN, Hijmans AG, van Sommeren-Zondag DF, Jansen AP Stability of frozen liquid control sera for assay of cholesterol in highdensity lipoproteins. Clin Chem $1982 ; 28: 155-7$.

${ }^{11}$ Demacker PN, Vos-Janssen HE, Hijmans AG, van't Laar A, Jansen AP.
Measurement of high-density lipoprotein cholesterol in serum: Comparison of six isolation methods combined with enzymic cholesterol analysis. Clin Chem 1980;13:1780-6.

${ }^{12}$ Friedewald WT, Levy RI, Fredrickson DS. Estimation of the concentration of low density lipoprotein cholesterol in plasma, without use of the preparative ultracentrifuge. Clin Chem 1972;18:499-502.

${ }^{13}$ Krauss RM, Lindgren FT, Silvers A, Jutagir R, Bradley DD. Changes in serum high density lipoproteins in women on oral contraceptive drugs. Clin Chim Acta 1977;80:465-70.

14 Schade RW, Meuwese JP, Thoben AJ, Demacker PN. HDL-cholesterol during oral contraception. Lancet $1978 ; \mathrm{ii}: 40$.

${ }^{15}$ Meerloo JM, Billmoria JD. High density lipoprotein cholesterol levels in peripheral vascular disease and in women on oral contraception. Atherlosclerosis 1979 ;33:267-9.

${ }^{16}$ Hennekens CH, Denis DA, Castelli WP, et al. Oral contraceptive use and fasting triglyceride, plasma cholesterol and HDL-cholesterol. Circulation $1979 ; 60: 486-9$.

${ }^{17}$ Larsson-Cohn U, Wallentin L, Zador G. Effects of three different combinations of ethinyl estradiol and levenorgestrel on plasma lipids and high density lipoproteins. Acta Obstet Gynecol Scand 1979;88: suppl $57-60$.

18 Bierenbaum ML, Fleischman AI, Stier A, et al. Increased platelet aggregation and decreased high density lipoprotein cholesterol in women on oral contraceptives. Am f Obstet Gynecol 1979;134:638-41.

19 Arntzenius AC, van Gent CM, van der Voort H, Stegerhoek CI, Styblo K. Reduced high-density lipoprotein in women aged 40-41 using oral contraceptives. Lancet 1978; i:1221-3.

${ }^{20}$ Leffler HH, McDougal CH. Estimation of cholesterol in serum by means of improved technics. Techn Bull Regist Med Techn 1963;33:19-23.

${ }^{21}$ Duboff GS, Stevenson WW. An ultramicro method for the estimation of plasma cholesterol. Clin Chem $1962 ; 8: 105-12$.

${ }^{22} \mathrm{Kim} \mathrm{HJ}$, Kalkhoff RK. Changes in lipoprotein composition during the menstrual cycle. Metabolism 1979;28:663-8.

${ }^{23}$ Barclay M, Barclay RK, Skipsi VP, et al. Fluctuations in human serum lipoprotein during the normal menstrual cycle. Biochem $\mathcal{f} 1965 ; 96 ; 205-9$.

(Accepted 5 February 1982)

\title{
Production of 6-oxo-prostaglandin $F_{1^{\alpha}}$ and prostaglandin $E_{2}$ by isolated glomeruli from normal and diabetic rats
}

\author{
SUSAN P ROGERS，RICHARD G LARKINS
}

\begin{abstract}
Production of 6-oxo-prostaglandin $F_{1 \alpha}$ (6-oxo-PGF $\left.F_{1}\right)$ and prostaglandin $\mathrm{E}_{2}\left(\mathrm{PGE}_{2}\right)$ was measured by radioimmunoassay in supernatants of isolated glomeruli from rats with streptozocin-induced diabetes and non-diabetic rats. Production of 6-oxo-PGF ${ }_{1}$ by discs of aortas from these rats was measured at the same time. As shown before, aortic discs from diabetic rats produced significantly less 6-oxo-PGF $1 \alpha$ than aortic discs from nondiabetic rats (diabetic $1.99 \pm S E M 0.27 \mathrm{ng}$ v non-diabetic $2.92 \pm 0.46 \mathrm{ng} / \mathrm{mg}$ net weight aorta; $\mathrm{p}<0.05)$. In contrast production of 6-oxo-PGF $1 \alpha$ by isolated glomeruli was not reduced in the diabetic rats (diabetic $77 \pm 7 \mathrm{pg} v$ nondiabetic $70 \pm 8 \mathrm{pg} / \mu \mathrm{g}$ glomerular DNA). Similarly production of $\mathrm{PGE}_{2}$ was not diminished in the diabetic glomeruli (diabetic $1.20 \pm 0 \cdot 15 \mathrm{ng} v$ non-diabetic $0.91 \pm 0.12 \mathrm{ng} / \mu \mathrm{g}$ glomerular DNA).

It is concluded that regional differences in production of prostacyclin and 6-oxo-PGF ${ }_{1}$ occur in experimental diabetes. Diminished prostacyclin production may con-
\end{abstract}

\footnotetext{
University of Melbourne Department of Medicine, Repatriation General Hospital, Heidelberg, Victoria 3081, Australia

SUSAN P ROGERS, MSC, research assistant RICHARD G LARKINS, PHD, FRACP, first assistant
}

tribute to the increased susceptibility of diabetic patients to atherosclerosis but is less likely to have a role in the pathogenesis of microangiopathy.

\section{Introduction}

Several groups, including our own, have shown that the production of prostacyclin $\left(\mathrm{PGI}_{2}\right)$ by aortas from diabetic rats is diminished. ${ }^{1-6}$ As $\mathrm{PGI}_{2}$ is a potent inhibitor of platelet aggregation, ${ }^{7}$ the deficiency in production of $\mathrm{PGI}_{2}$ may contribute to the high incidence of vascular disease in diabetes. The relevance of these findings in diabetic rat aortas has been challenged by reports showing no decrease in circulating 6-oxo-prostaglandin $F_{1 \alpha}$ (6-oxo-PGF $F_{1}$ ) (the stable metabolite of $\mathrm{PGI}_{2}$ ) in human diabetes. ${ }^{8}{ }^{9}$ This suggests either that the observations in diabetic rats are not relevant to human diabetes or that regional differences in $\mathrm{PGI}_{2}$ production occur. In particular there might be differences in $\mathrm{PGI}_{2}$ production between large arteries and the microvascular circulation. We have tested this second possibility by measuring the production of $6-$ oxo- $^{-\mathrm{PGF}_{1} \alpha}$ by glomeruli and aortas from the same group of diabetic rats.

\section{Animals and methods}

Diabetes was induced in nine age-matched male Sprague-Dawley rats (weight about $250 \mathrm{~g}$ ) as described. ${ }^{6}$ Between 31 and 41 days áfter intravenous injection of streptozocin $60 \mathrm{mg} / \mathrm{kg}$, one streptozocin- 